\title{
FOSFOGESSO NO CRESCIMENTO DE MUDAS DE MAMÃO
}

\author{
Marcelo Romero Ramos da Silva ${ }^{1}$, Monielly Campos Bertolaia ${ }^{2}$, Luiz Sergio Vanzela ${ }^{3}$, \\ Gisele Herbst Vazquez ${ }^{4}$
}

\footnotetext{
${ }^{1}$ Professor do Curso de Agronomia, Departamento de Fitotecnia, Universidade Camilo Castelo Branco UNICASTELO, Fernandópolis, São Paulo. E-mail: marceloromero357@ gmail.com

${ }^{2}$ Engenheira Agrônoma, Departamento de Fitotecnia, Universidade Camilo Castelo Branco - UNICASTELO, Fernandópolis, São Paulo.

${ }^{3}$ Professor Titular, Mestrado em Ciências Ambientais, Universidade Camilo Castelo Branco - UNICASTELO, Fernandópolis, São Paulo.

${ }^{4}$ Professora Titular, Mestrado em Ciências Ambientais, Universidade Camilo Castelo Branco - UNICASTELO, Fernandópolis, São Paulo.
}

RESUMO: A produção de mudas de mamão é uma etapa de grande importância para o sucesso de um pomar, visto que a qualidade da muda está relacionada ao potencial produtivo das plantas adultas, proporcionando maiores rendimentos quantitativos e qualitativos. $\mathrm{O}$ objetivo do presente trabalho foi avaliar o efeito de diferentes doses de fosfogesso na produção de mudas de mamão da cultivar Sunrise Solo Line 72/12, em condição de ambiente protegido. O experimento foi conduzido no viveiro de mudas da Fazenda de Ensino e Pesquisa da Universidade Camilo Castelo Branco, campus Fernandópolis/SP. O delineamento experimental utilizado foi de blocos ao acaso, com cinco tratamentos $(0 ; 0,020 ; 0,060 ; 0,100$ e $0,140 \mathrm{~kg}$ recipiente ${ }^{-1}$ de fosfogesso) e quatro repetições. As variáveis mensuradas foram: comprimento da parte aérea e da raiz $(\mathrm{cm})$; massa úmida e seca da parte aérea $(\mathrm{g})$ e massa úmida e seca de raiz (g) aos 75 dias após a semeadura. Concluiu-se que as doses de 0,091 e $0,108 \mathrm{~kg}$ recipiente $^{-1}$ de fosfogesso resultam em mudas de mamão com maior desenvolvimento e massas úmida e seca da parte aérea e das raízes, respectivamente. A utilização do fosfogesso em viveiros de mamão é positiva por proporcionar a produção antecipada das mudas para plantio em campo.

Termos para indexação: Carica papaya L. Produtos alternativos. Produção de mudas. Ambiente de cultivo.

\section{FOSFOGESSOIN PAPAYA SEEDLINGS DEVELOPMENT}

\begin{abstract}
The papaya seedlings production is a step of great importance for the success of an orchard, since the quality of the seedling is related to the productive potential of the adult plants, providing greater quantitative and qualitative yields. The aim of this study was to evaluate the effect of different doses of fosfogesso in papaya seedlings from the Sunrise Solo 71/12 production, under greenhouse conditions. The experiment was conducted in the seedling nursery at the Teaching and Research Farm at the Universidade Camilo Castelo Branco, Campus Fernandópolis, SP. The experimental design used were random blocks, with five different treatments $\left(0 ; 0,020 ; 0,060 ; 0,100\right.$ and $0,140 \mathrm{~kg} \mathrm{bags}^{-1}$ of fosfogesso) and four
\end{abstract}

Cultura Agronômica, Ilha Solteira, v.26, n.1, p.42-52, 2017 
repetitions each. The variables measured were: plant's height and root length $(\mathrm{cm})$, wet and dry leaf's mass weight (g) and wet and dry root mass weight $(\mathrm{g}), 75$ days after sowing. It was concluded that the doses of 0.091 and $0.108 \mathrm{~kg} \mathrm{bags}^{-1}$ of fosfogesso resulted in papaya seedlings with higher development and wet and dry masses of shoots and roots. The use of fosfogesso in papaya nurseries is positive for providing the anticipated production of seedlings for field planting.

Index terms: Carica papaya L. Alternative products. Spread. Growing environment.

\section{INTRODUÇÃO}

No Brasil e em vários países da América tropical, o mamão destaca-se como uma fruta com grande potencial produtivo e interesse comercial, dado ao amplo mercado interno e a crescente demanda de exportação. Em 2013, a produção mundial de mamão atingiu 12,5 milhões de toneladas, sendo o Brasil o segundo maior produtor, com 12,6\% do total, comprovando as condições edafoclimáticas favoráveis para o cultivo desta frutífera (OLIVEIRA, 2000; FAOSTAT, 2015).

Um pomar de mamão apresenta um curto período de viabilidade, necessitando de renovação constante. Assim, é importante a busca por novas tecnologias de produção de mudas, com variedades mais resistentes a diversos problemas, dentre eles os fitossanitários, como a Phytophthora palmivora, causadora da podridão das raízes e de frutos no mamoeiro (LIMA et al., 2007).

A produção de mudas é um dos principais insumos para a exploração técnica e comercial do mamoeiro, que por ser uma cultura perene, poderá apresentar problemas durante todo o seu período de produção, caso a muda plantada não seja de qualidade. As mudas normalmente são produzidas em substrato que apresentam baixo ou nulo potencial de inóculo (microrganismos), seja pelo uso de doses elevadas de fertilizantes ou pelo uso de fumigantes, bem como, substratos inertes (TRINDADE et al., 2000; SARAIVA et al., 2011).

Um substrato deve apresentar boas características físicas, químicas e biológicas, possibilitando assim, um rápido crescimento da muda, elevada produção de matéria seca da parte aérea e radicular, dentre outras características fisiológicas. Para a obtenção de mudas de boa qualidade, a adubação adequada é de suma importância, refletindo no estado nutricional da planta, aumentando a produtividade dos pomares e, especialmente, interferindo na precocidade da primeira produção (YAMANISHI et al., 2004; PRADO et al., 2005; SARAIVA et al., 2011).

$\mathrm{Na}$ agricultura moderna, produtos alternativos como o fosfogesso têm sido testados com o objetivo de produzir mudas de mamoeiro de qualidade e em menor tempo. O fosfogesso, que é um subproduto da fabricação do ácido fosfórico, assemelha-se ao gesso natural, sendo ambos constituídos principalmente por sulfato de cálcio e enxofre. Esses nutrientes atuam de forma satisfatória no metabolismo das plantas, desempenhando papel fundamental na 
estrutura das proteínas, produzindo energia na fotossíntese e também na respiração das plantas em desenvolvimento (FERNANDES et al., 2010).

Até o presente momento, no Brasil, grande volume desse resíduo industrial é gerado e armazenado sem cobertura junto ao local de produção, não havendo nenhuma norma específica que regulamente a sua utilização, sendo apenas uma pequena parcela reutilizada, havendo assim, grande interesse na sua reciclagem (VILLAVERDE, 2008).

Neste contexto, o objetivo deste trabalho foi avaliar o efeito de doses de fosfogesso na produção de mudas de mamão da cultivar Sunrise Solo Line 72/12 em condição de ambiente protegido.

\section{MATERIAL E MÉTODOS}

O experimento foi conduzido na área experimental da Fazenda de Ensino e Pesquisa da Universidade Camilo Castelo Branco - UNICASTELO, Campus de Fernandópolis, SP, em ambiente protegido (viveiro telado), localizada nas coordenadas $20^{\circ} 16{ }^{\prime} 50^{\prime \prime}$ sul e $50^{\circ} 17^{\prime} 43^{\prime \prime}$ oeste e a uma altitude de $520 \mathrm{~m}$.

O clima da região, de acordo com a classificação de Koppen, é Aw (tropical úmido) (ROLIM et al., 2007), sendo caracterizada por um período de déficit hídrico de seis meses no ano, temperatura média de $23,5^{\circ} \mathrm{C}$, precipitação média anual de $1370 \mathrm{~mm}$ e umidade relativa média de 64,8\% (EMBRAPA, 2007).

A classificação do solo utilizado para a condução do experimento é Argissolo Vermelho-Amarelo (OLIVEIRA et al., 1999), cujas características químicas determinadas por análise de rotina, na profundidade de $0-20 \mathrm{~cm}$, encontram-se na Tabela 1.

Tabela 1. Resultado da análise química do solo utilizado no substrato.

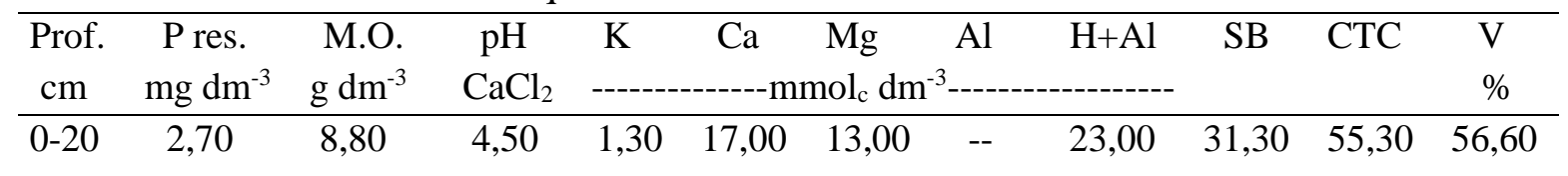

Fonte: Laboratório de Fertilidade do Solo (UNICASTELO/Fernandópolis/SP).

O delineamento experimental utilizado foi de blocos inteiramente casualizados, com cinco tratamentos (doses de 0;0,020;0,060;0,100 e 0,140 kg recipiente ${ }^{-1}$ de fosfogesso) e quatro repetições. Cada parcela foi constituída por 10 recipientes por repetição, totalizando 200 plantas no experimento.

O recipiente utilizado para a semeadura das sementes de mamão foi saquinho de polietileno preto de $78,53 \mathrm{~cm}^{3}(10 \times 20 \mathrm{~cm})$, furado lateralmente e com capacidade para $500 \mathrm{~g}$. O substrato utilizado foi solo de subsuperficie, sendo colocado manualmente no recipiente até a superfície com o intuito de simular o ambiente natural. Não foi realizada a adubação de correção de solo, para que o mesmo não interferisse no efeito dos tratamentos. Antes do preenchimento dos recipientes foi realizada a mistura manual do solo com fosfogesso de

Cultura Agronômica, Ilha Solteira, v.26, n.1, p.42-52, 2017 
acordo com os tratamentos. A composição química do fosfogesso é: 17,7\% de enxofre (S), $30,90 \%$ de óxido de cálcio $(\mathrm{CaO})$ e $0,70 \%$ de fósforo $\left(\mathrm{P}_{2} \mathrm{O}_{5}\right)$ (RAIJ, 1988).

$\mathrm{Na}$ semeadura foram utilizadas sementes tratadas $(0,75 \%$ de Captam) da cultivar Sunrise Solo Line 72/12 (grupo solo) com 71\% de germinação e 99,9\% de pureza, conforme dados do fabricante. A semeadura foi realizada com três sementes, com posterior desbaste aos 20 dias após a emergência, objetivando-se manter uma plântula por recipiente.

Os tratos culturais recomendados para a cultura foram: irrigação realizada no período da manhã e tarde com microaspersão (vazão: $52 \mathrm{~L} \mathrm{~h}^{-1}$ ); controle manual de plantas daninhas e inspeções diárias para a detecção de pragas e doenças.

As mudas foram retiradas e avaliadas aos 75 dias após a semeadura, sendo analisadas as seguintes variáveis: comprimento da parte aérea $(\mathrm{cm})$, medida a partir do colo da planta até o meristema apical; comprimento de raiz $(\mathrm{cm})$, medida a partir do colo da planta até a extremidade da raiz; massa úmida e seca da parte aérea (g) e massa úmida e seca de raiz (g), por meio de pesagens antes e após a secagem em estufa à temperatura de $65^{\circ} \mathrm{C}$ por 48 horas.

Como o fator avaliado é quantitativo (diferentes doses de fosfogesso), a análise estatística consistiu em análise de variância seguida de análise de regressão, sendo avaliados os modelos linear e quadrático ao nível de 5\% de probabilidade. Todas as análises foram realizadas com o auxílio do software SISVAR (FERREIRA, 2008).

\section{RESULTADOS E DISCUSSÃO}

Na Tabela 2 pode-se verificar que todas as variáveis apresentaram interferência significativa das doses de fosfogesso $(\mathrm{p}<0,01)$. Estes resultados comprovam que o fosfogesso é uma fonte de nutrientes para as plantas, atuando como fornecedora de fósforo, enxofre e cálcio para solos tropicais, permitindo assim um maior desenvolvimento das plantas e do sistema radicular, principalmente para a produção de mudas de mamão.

Tabela 2. Resultado da análise de variância do comprimento da parte aérea (CA), comprimento de raiz (CR), massa úmida da raiz (MUR), massa seca da raiz (MSR), massa úmida aérea (MUA) e massa seca aérea (MAS) em função das doses de fosfogesso (DF) na produção de mudas de mamão.

\begin{tabular}{ccc}
\hline \multirow{2}{*}{ Variável } & \multicolumn{2}{c}{ Teste F para doses de fosfogesso } \\
& $\mathrm{p}^{*}$ & $\mathrm{CV}(\%)^{* *}$ \\
\hline CA & $\mathrm{p}<0,01$ & 10,78 \\
CR & $\mathrm{p}<0,01$ & 5,06 \\
MUR & $\mathrm{p}<0,01$ & 28,10 \\
MSR & $\mathrm{p}<0,01$ & 20,48 \\
MUA & $\mathrm{p}<0,01$ & 13,10 \\
MAS & $\mathrm{p}<0,01$ & 26,63 \\
\hline
\end{tabular}

Obs: *p (nível de significância), **CV (coeficiente de variação).

Cultura Agronômica, Ilha Solteira, v.26, n.1, p.42-52, 2017 
A melhor resposta do comprimento da parte aérea das plantas em função das doses de fosfogesso foi a quadrática (Figura 1A), onde o maior valor $(45,0 \mathrm{~cm})$ é esperado com a dose de $0,093 \mathrm{~kg}$ recipiente ${ }^{-1}$. Silva et al. (2016) avaliando diversos compostos acrescidos ao substrato de mudas de mamão, dentre eles a aplicação de $0,008 \mathrm{~kg}$ recipiente $^{-1}$ de fosfogesso, obtiveram um comprimento médio da parte aérea de apenas 16,07 cm aos 140 dias após a semeadura, diferenciando-se desta pesquisa. Neste experimento, a utilização de uma dose maior de fosfogesso provavelmente estimulou o crescimento das raízes, garantindo maior absorção de água, nutrientes e desenvolvimento da parte aérea das plantas. Em relação à testemunha, o uso de $0,093 \mathrm{~kg}$ recipiente ${ }^{-1}$ de fosfogesso quase que triplicou o crescimento das mudas, o que garantiria a produção de mudas em um menor tempo (número de dias).

O fósforo é essencial na sobrevivência e no metabolismo das plantas, desempenhando papel importante na respiração e na fotossíntese, além de ser fonte energética para todos os processos metabólicos das plantas e componente estrutural dos ácidos nucleicos, coenzimas, moléculas de DNA e RNA (GRANT et al., 2001). Esse nutriente acelera a formação de raízes e limitações deste nutriente no início do crescimento vegetativo, ou seja, na fase de mudas, pode resultar em restrições no desenvolvimento, dos quais a planta não se recupera posteriormente, além de ocasionar menor produtividade, qualidade e senescência precoce (MARSCHNER, 1997; TAIZ; ZEIGER, 2004; SOUZA et al., 2013; MALAVOLTA, 2006).

O enxofre fornecido pelo fosfogesso também podem ter favorecido o maior crescimento das mudas. Silva et al. (1986) em um experimento com gravioleira observaram que as mudas cultivadas em solução com omissão de enxofre foram visivelmente menores do que as cultivadas em solução completa.

Já o cálcio, é importante na preservação da capacidade de absorção das raízes mediante a manutenção da integridade da membrana plasmática, aumentando o acúmulo de nutrientes pela planta (MALAVOLTA, 2006), onde plantas deficientes em cálcio possuem baixo crescimento e desenvolvimento do sistema radicular, apresentando menor absorção de nutrientes e água, estando sujeitas a deficiências mineral e hídrica (LAMBAIS, 2006).

Da mesma forma, a resposta do comprimento de raízes em função das doses de fosfogesso foi quadrática (Figura 1B), onde o máximo comprimento de raízes $(35,3 \mathrm{~cm})$ pode ser esperado para a dose de $0,089 \mathrm{~kg}$ recipiente $^{-1}$, a partir da qual, ocorrem decréscimos nos valores, sendo que em relação à testemunha, o uso desta dose foi capaz de elevar em mais de $44 \%$ o sistema radicular das mudas, favorecendo a antecipação de seu plantio em campo.

Resultados semelhantes foram obtidos por Teixeira et al. (2012), que observaram que o comprimento do sistema radicular do caju foi influenciado positivamente $(22,26 \mathrm{~cm}) \mathrm{com}$ o aumento da dose $\left(80 \mathrm{~g} \mathrm{~m}^{-3}\right)$ de enxofre no substrato utilizado. Para Malavolta (1989), as plantas não conseguem aproveitar mais que $10 \%$ do fósforo total aplicado, pois nos solos tropicais ácidos, ricos em ferro e alumínio, ocorre a absorção deste elemento; o fósforo na planta estimula o crescimento das raízes, garantindo um crescimento inicial vigoroso.

Cultura Agronômica, Ilha Solteira, v.26, n.1, p.42-52, 2017 
O cálcio, por sua vez, é um nutriente com papel preponderante no crescimento radicular das plantas (RITCHEY et al., 1982). A importância do cálcio para as plantas deve-se ao fato de que cerca de $60 \%$ do cálcio celular está presente na parede celular (TOBIAS et al., 1993).
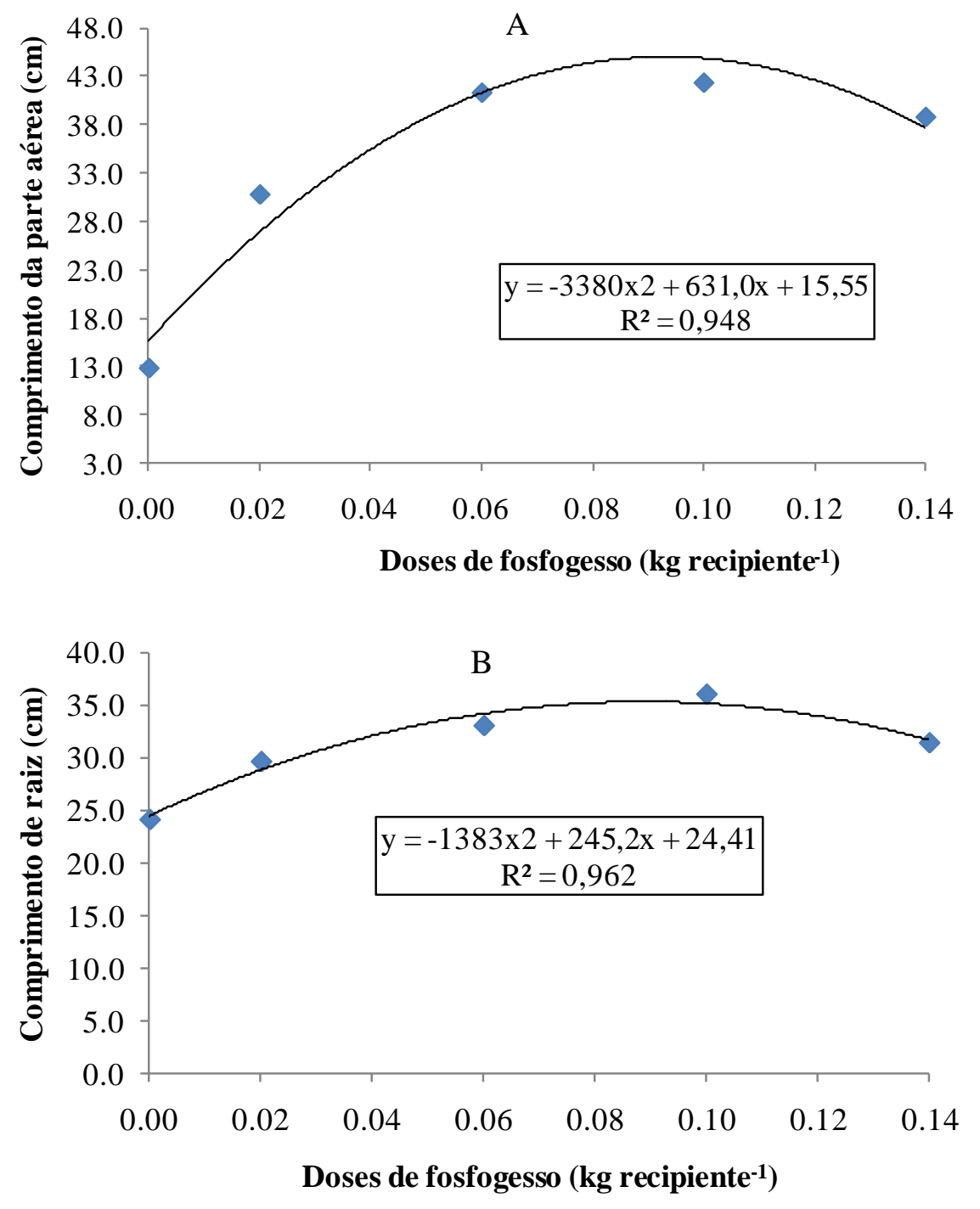

Figura 1. Resposta do comprimento da parte aérea (A) e do comprimento da raiz (B) em função das doses de fosfogesso aplicado nas mudas de mamão.

Para a parte aérea, as melhores respostas observadas das massas úmida e seca em função das doses de fosfogesso foram quadráticas (Figuras 2A e 2B). A máxima massa úmida esperada para a parte aérea $(15,579 \mathrm{~g})$ é na dose de $0,102 \mathrm{~kg}$ recipiente ${ }^{-1}$, enquanto a máxima massa seca $(1,707 \mathrm{~g})$ é esperada na dose de $0,106 \mathrm{~kg}$ recipiente $^{-1}$. Silva et al. (2016) determinaram que o efeito de aplicações de composto orgânico $\left(0,012 \mathrm{~kg}_{\text {recipiente }}{ }^{-1}\right) \mathrm{e}$ fosfogesso $\left(0,008 \mathrm{~kg}\right.$ recipiente $\left.{ }^{-1}\right)$ acarretou um aumento na massa seca das folhas do mamoeiro $(0,200 \mathrm{~g})$, tornando a área foliar maior e com melhor aproveitamento dos raios solares. 

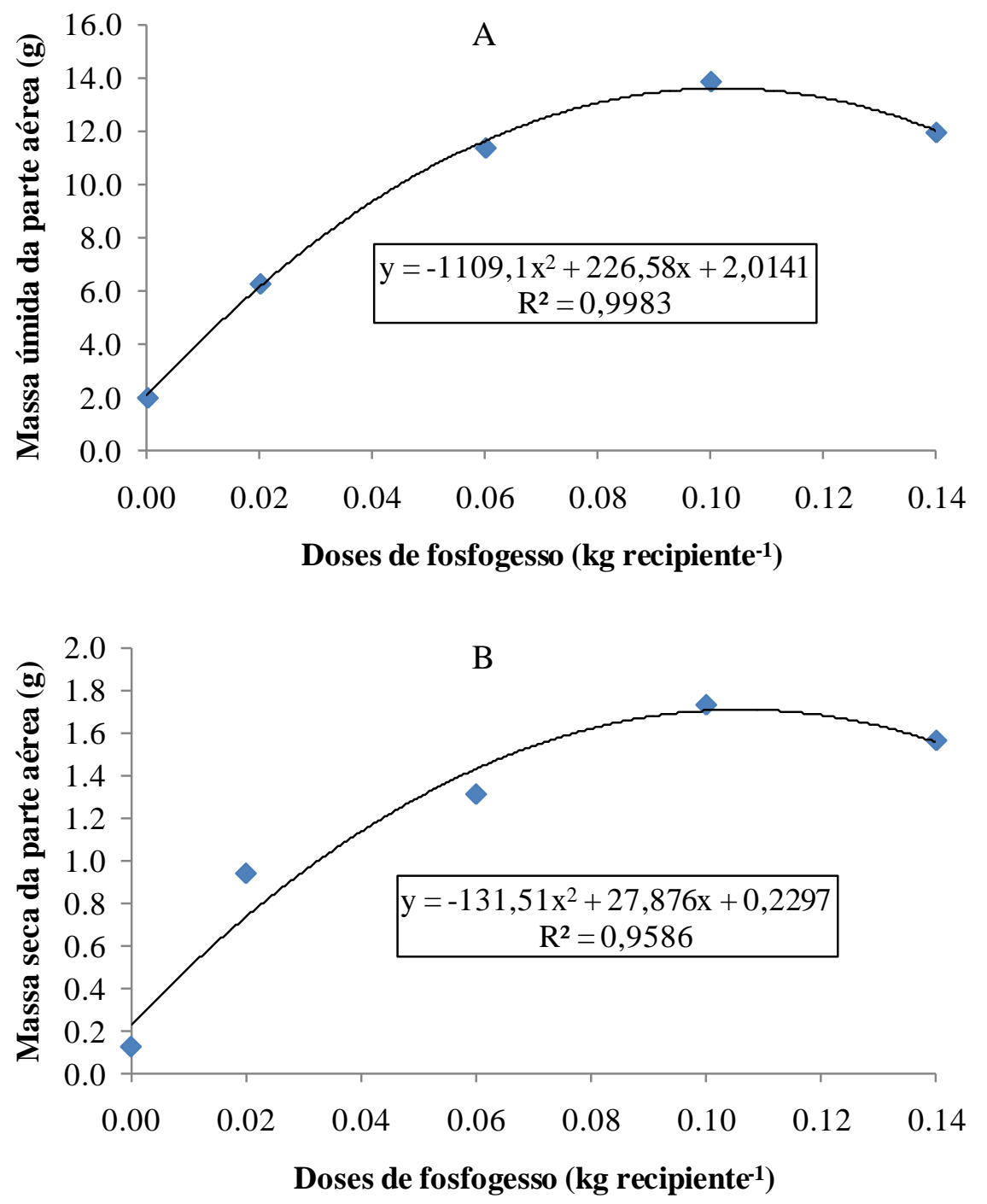

Figura 2. Resposta da massa úmida da parte aérea (A) e da massa seca da parte aérea (B) em função das doses de fosfogesso aplicado nas mudas de mamão.

A produção de massa úmida e seca da parte aérea é uma das primeiras variáveis a se avaliar quando se busca informações sobre determinada cultivar, sendo característica positiva para as plantas frutíferas. O aumento da massa indica acréscimos na taxa fotossintética e, conseqüentemente, da produção de assimilados pela planta, favorecendo o desempenho da muda quando transplantada para o campo. A obtenção de uma área foliar maior pode estar relacionada ao acúmulo de fotoassimilados que é de grande importância no processo metabólico, auxiliando no papel central nas reações que envolvem o ATP (SARAIVA et al., 2011).

Garcia et al. (2011) verificaram incrementos da massa seca da folha de maracujazeiro amarelo com o aumento das dosagens de enxofre $\left(0,53 \mathrm{~kg} \mathrm{~m}^{-3}\right)$, promovendo seu maior valor $\left(1,68 \mathrm{~g} \mathrm{muda}^{-1}\right)$, e que doses superiores a esta, proporcionaram a redução no seu peso. Comportamento semelhante foi observado neste experimento, visto que o enxofre participa 
de um número grande de compostos e reações, e dependendo da sua concentração é capaz de provocar inúmeros distúrbios metabólicos, sendo um deles a diminuição na fotossíntese e nas reações que envolvem o ATP (MALAVOLTA, 2006).

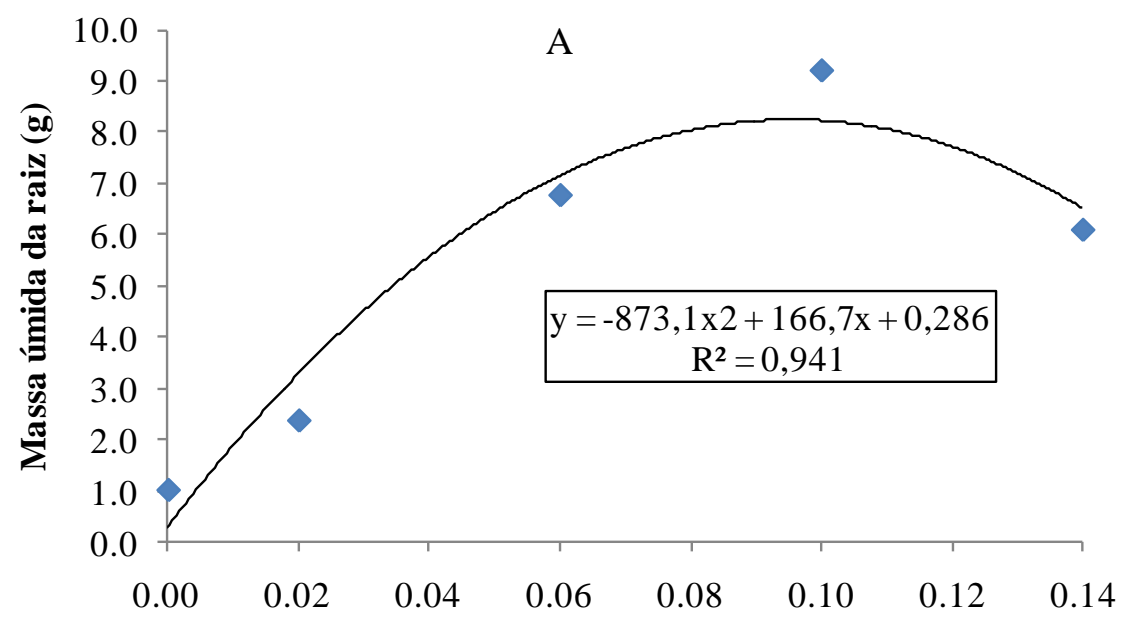

Doses de fosfogesso (kg recipiente-1)

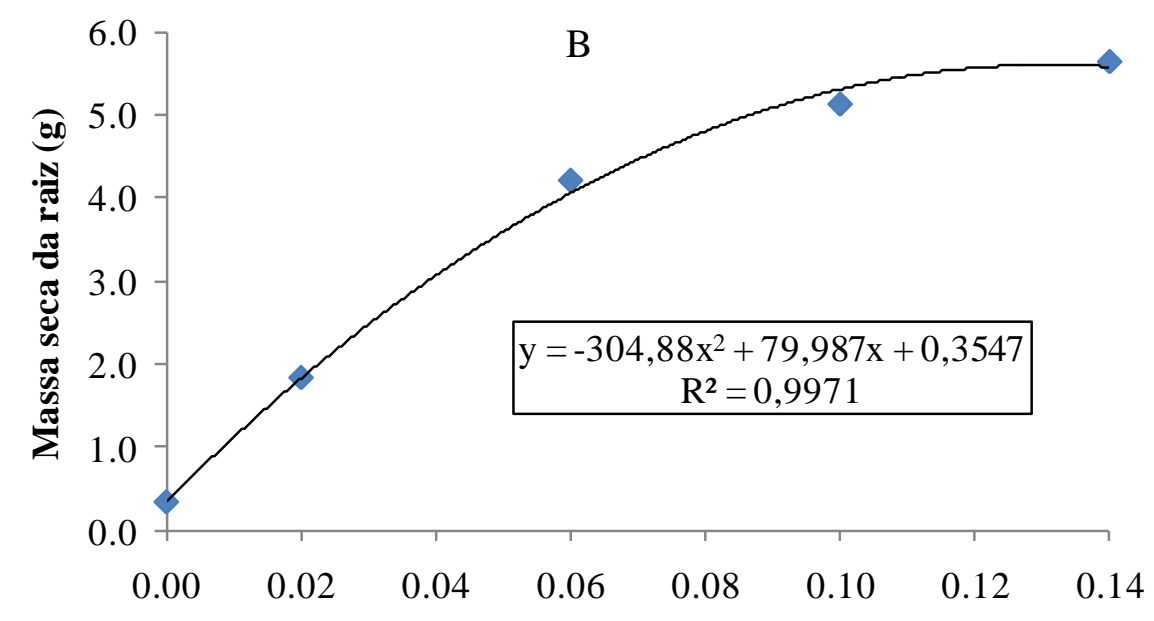

Doses de fosfogesso (kg recipiente-1)

Figura 3. Resposta da massa úmida da raiz (A) e da massa seca da raiz (B) em função das doses de fosfogesso aplicado nas mudas de mamão.

Observou-se também, que as melhores respostas das massas úmida e seca de raíz em função das doses de fosfogessso foram quadráticas (Figuras 3A e 3B). A máxima massa úmida de raízes $(8,243 \mathrm{~g})$ é esperada para a dose de $0,095 \mathrm{~kg}$ recipiente ${ }^{-1}$. E para a massa seca de raízes, o valor máximo alcançado $(5,601 \mathrm{~g})$ é esperado para a dose de $0,131 \mathrm{~kg}$ recipiente 1 .

Saraiva et al. (2011) utilizando diferentes doses de adubação fosfatada $(0 ; 2 ; 4 ; 6 ; 8 \mathrm{~kg}$ $\mathrm{m}^{-3}$ ) afirmaram que o fósforo participa de várias reações na planta, exercendo grande importância no processo de transferência de energia e, conseqüentemente, no desenvolvimento de raízes, como observado neste experimento, com o uso de fosfogesso.

Cultura Agronômica, Ilha Solteira, v.26, n.1, p.42-52, 2017 
Portanto, os resultados demonstram o efeito positivo do fosfogesso no aumento da matéria seca das raízes do mamoeiro, o que deve se refletir em maior capacidade de absorção de nutrientes e como já observado, no maior desenvolvimento da parte aérea e precocidade de utilização em campo.

Assim, levando-se em consideração as melhores doses de fosfogesso para o crescimento da parte aérea e das raízes $(0,093$ e $0,089 \mathrm{~kg})$, a recomendação seria de 0,091 kg recipiente ${ }^{-1}$, já em relação às massas úmidas e secas da parte aérea e da raiz $(0,102 ; 0,106 ; 0,095$ e 0,131 $\mathrm{kg}$ ) seria de $0,108 \mathrm{~kg}$ recipiente $^{-1}$.

\section{CONCLUSÃO}

De acordo com os resultados obtidos, conclui-se que as doses de 0,091 e 0,108 kg recipiente ${ }^{-1}$ de fosfogesso resultam em mudas de mamão com maior desenvolvimento e massa úmida e seca da parte aérea e das raízes, respectivamente.

A utilização do fosfogesso em viveiros de mamão é positiva por proporcionar a produção antecipada das mudas para plantio em campo.

\section{REFERÊNCIAS BIBLIOGRÁFICAS}

EMBRAPA. Banco de dados climáticos do Brasil. Brasília: Embrapa Monitoramento por Satélites, 2007. Disponível em: http://www.bdclima.cnpm.embrapa.br/. Acesso em: 12 jan. 2016.

FAOSTAT. Food and Agriculture Organization of the United Nations. 2015. Disponível em: http://faostat3.fao.org/home/e. Acesso em: 12 jan. 2016.

FERNANDES, F. R. C.; LUZ, A. B.; CASTILHOS, Z. C. Agrominerais para o Brasil. Rio de Janeiro: CETEM/MCT, 2010. 380 p.

FERREIRA, D. F. Um programa para análise estatística e ensino de estatística. Revista Symposium, Lavras, v. 6, n. 1, p. 36-41, 2008.

GARCIA, K. G. V.; SILVA, C. P.; SIlVA, R. M.; MENDONÇA, V.; TOSTA, M. S. Desenvolvimento inicial de mudas de maracujazeiro-amarelo em função de doses crescentes de enxofre. Revista Verde, Mossoró, v. 6, n. 2, p.131-134, 2011.

GRANT, C. A.; PLATEN, D. N.; TOMAZIEWICZ, D. J.; SHEPPARD, S. C. A importância do fósforo no desenvolvimento inicial da planta. Informações Agronômicas, Piracicaba, n. 95, p.1-5, 2001.

LAMBAIS, M. R. Unraveling the signaling and signal transduction mechanisms controlling arbuscular mycorrhiza development. Scientia Agricola, Piracicaba, v. 63, n. 4, p.405-413. 2006.

Cultura Agronômica, Ilha Solteira, v.26, n.1, p.42-52, 2017 
LIMA, J. F.; PEIXOTO, C. P.; LEDO, C. A. S. Índices fisiológicos e crescimento inicial de mamoeiro (Carica papaya L.) em casa de vegetação. Ciência e Agrotecnologia, Lavras, v. 31, n. 5, p.1358-1363, 2007.

MALAVOLTA, E. ABC da adubação. São Paulo: Agronômica Ceres, 1989. 292 p.

MALAVOLTA, E. Elementos da nutrição mineral de plantas. São Paulo: Agronômica Ceres, 2006. 638 p.

MARSCHNER, H. Mineral nutrition of higher plants. 2. ed. London: Academic Press, 1997. 889 p.

OLIVEIRA, J. B.; CAMARGO, M. N.; ROSSI, M.; CALDERANO FILHO, B. Mapa pedológico do Estado de São Paulo: legenda expandida. Campinas: Instituto Agronômico/ EMBRAPA Solos, 1999. 64 p.

OLIVEIRA, P. R. A. Efeito do fósforo e zinco na nutrição de mamoeiro e mangabeira. 2000. 184 f. Tese (Doutorado em Fitotecnia) - Universidade Federal de Lavras, Lavras, 2000.

PRADO, R. M.; VALE, D. W.; ROMUALDO, L. M. Fósforo na nutrição e produção de mudas de maracujazeiro. Acta Scientiarum Agronomy, Maringá, v. 27, n. 3, p.493-498, 2005 .

RAIJ, B. V. Gesso agrícola na melhoria do ambiente radicular no subsolo. São Paulo: ANDA - Associação Nacional para Difusão de Adubos e Corretivos Agrícolas, 1988. 88 p.

RITCHEY, K. D.; SILVA, J. E.; COSTA, U. F. Calcium deficiency in clayey B horizons of savanna oxisols. Soil Science, Baltimore, v. 133, n. 6, p.378-382, 1982.

ROLIM, G. S.; CAMARGO, M. B. P.; LANIA, D. G.; MORAES, J. F. L. Classificação climática de köppen e de thornthwaite e sua aplicabilidade na determinação de zonas agroclimáticas para o estado de São Paulo. Bragantia, Campinas, v. 66, n. 4, p.711-720, 2007.

SARAIVA, K. R.; NASCIMENTO, R. S.; SALES, F. A. L.; ARAÚJO, H. F.; VIEIRA, C. F. N.; LIMA, A. D. Produção de mudas de mamoeiro sob doses de adubação fosfatada utilizando como fonte superfosfato simples. Revista Brasileira de Agricultura Irrigada, Fortaleza, v. 5, n. 4, p.376 - 383, 2011.

SILVA, A. Q.; SILVA, H.; ROQUE, M. L.; MALAVOLTA, E. Nutrição mineral da graviola (Annona muricata L). I. Sintomas de carência nutricionais. In: CONGRESSO BRASILEIRO DE FRUTICULTURA, 8., 1986, Brasília. Anais... Brasília: SBF, 1986. v. 2, p. 297-303.

SILVA, M. R. R.; VANZELA, L. S.; PINHEIRO, L. C.; SOUZA, J. F. S. Efeito de diferentes compostos na produção de mudas de mamoeiro. Nucleus, Ituverava, v. 13, n. 1, p.63-70, 2016.

SOUZA, N. H.; MARCHETTI, M. E.; CARNEVALI, T. O.; RAMOS, D. D.; SCALON, S. P. Q.; SILVA, E. F. Estudo nutricional da canafistula (I): crescimento e qualidade de mudas

Cultura Agronômica, Ilha Solteira, v.26, n.1, p.42-52, 2017 
em resposta à adubação com nitrogênio e fósforo. Revista Árvore, Viçosa, v. 37, n. 4, p.717724, 2013.

TAIZ, L.; ZEIGER, E. Fisiologia vegetal. 3. ed. Porto Alegre: Artmed, 2004. 719 p.

TEIXEIRA, F. J. V.; LIMA, M. F. P.; PAIVA, J. C. O.; DANTAS; L. L. G. R.; TOSTA, M. S. Doses de enxofre no desenvolvimento inicial de cajueiro comum. ACSA - Agropecuária Científica no Semi-Árido, Campina Grande, v. 8, n. 4, p.66-70, 2012.

TOBIAS, R. B.; CONWAY, W. S.; SAMS, C. E.; GROSS, K. C.; WHITAKER, B. D. Cell wall composition of calcium-treated apples inoculated with Botrytis cinerea. Phytochemistry, Rossinière, v. 32, n. 1, p.35-39, 1993.

TRINDADE, V. A.; FARIA, G. N.; ALMEIDA, P. F. Uso de esterco no desenvolvimento de mudas de mamoeiro colonizada com fungos micorrízicos. Pesquisa Agropecuária Brasileira. Brasília, v. 35, n. 7, p.1389- 1394, 2000.

VILLAVERDE, L. F. Avaliação da exposição externa em residência construída com fosfogesso. 2008. 65 f. Dissertação (Mestrado em Ciências na Área de Tecnologia Nuclear Aplicações) - Instituto de Pesquisas Energéticas e Nucleares, Universidade de São Paulo, São Paulo, 2008.

YAMANISHI, O. K.; FAGUNDES, G. R.; MACHADO FILHO, J. A.; VALONE, G. V. Efeito de diferentes substratos e duas formas de adubação na produção de mudas de mamoeiro. Revista Brasileira Fruticultura, Jaboticabal, v. 26, n. 2, p.276-279, 2004. 